\title{
Immunity to influenza in ferrets
}

\section{Immunization with inactivated virus in adjuvant 65}

\author{
By C. W. POTTER, C. McLAREN AND S. L. SHORE* \\ Virus Research Laboratory, Lodge Moor Hospital, Sheffield, Yorkshire
}

(Received 19 June 1972)

\section{SUMMARY}

Ferrets infected with influenza virus A2/Hong Kong/3/68 responded with a febrile reaction; the temperature was elevated by $1.0^{\circ} \mathrm{C}$. or greater to a level of $40^{\circ} \mathrm{C}$. or more. In addition, relatively high titres of virus were recovered from nasal washings taken 3 days after virus infection, serum antibody was produced, increased nasal protein was detected and nasal washings contained both HI and neutralizing antibody. Of four ferrets immunized with $400 \mathrm{CCA}$ units of inactivated influenza virus A2/Aichi/2/68 in saline, only one produced detectable serum HI antibody, and none produced detectable nasal antibody. These ferrets were subsequently found to be susceptible to intranasal infection with influenza virus A2/Hong Kong/3/68. Thus, the temperature response, the titre of virus recovered from nasal washings and the serum HI antibody response found after virus infection was similar to that found after infection of non-immunized ferrets. However, the increase in protein concentration and the titre of $\mathrm{HI}$ and neutralizing antibody found in nasal washings after virus infection was detectably less than that found after virus infection of non-immunized ferrets.

Four ferrets were immunized with $400 \mathrm{CCA}$ units of inactivated A2/Aichi/2/68 virus in adjuvant 65 , and these ferrets produced relatively high titres of serum HI antibody but no detectable nasal antibody. After subsequent virus infection with influenza virus $\mathrm{A} 2 / \mathrm{Hong} \mathrm{Kong} / 3 / 68$, these ferrets showed a modified temperature response, reduced titres of virus in nasal washings compared to that found in nasal washings from non-immunized ferrets, no increase in nasal protein and no detectable nasal HI antibody. Thus, immunization with inactivated virus in adjuvant 65 resulted in a significant modification of the response of ferrets to challenge virus; however, the immunity was not complete, and appreciably less than that found after infection with live homologous virus.

\section{INTRODUCTION}

Previous studies have shown that ferrets were highly susceptible to infection with influenza virus (Smith, Andrewes \& Laidlaw, 1933; Haff, Schriver \& Stewart, 1966; Marois, Boudreault, Difranco \& Pavizanis, 1971). Thus, ferrets inoculated with influenza virus $\mathrm{A} 2 / \mathrm{Hong} \mathrm{Kong} / 3 / 68$ responded with a sharp rise in temperature, rhinitis, and produced both nasal and serum antibody (Potter et al. 1972a, $b$ ).

* Visiting Research Fellow from Centre for Disease Control, Atlanta, Georgia, U.S.A. 
These animals may be used as a model for the study of immunization against influenza, since ferrets immune to infection with influenza virus failed to exhibit any of the above symptoms after intranasal infection with virulent virus (Francis \& Stuart-Harris, 1938; Potter et al. 1972a).

In earlier studies, immunization of ferrets with inactivated A2/Hong Kong vaccine in saline failed to stimulate serum antibody, and the animals were completely susceptible to later infection with live virus (Potter et al. 1972a,b). In the present study, we report the results of immunization of ferrets with influenza virus A2/Aichi/2/68 in adjuvant 65 (Weibel et al. 1967; Stokes et al. 1969; Woodhour et al. 1969) and the effects of subsequent challenge with influenza virus A2/Hong Kong/3/68. The results are compared with the results of infection with virulent influenza virus on ferrets previously immunized with A2/Aichi/2/68 in saline and on non-immunized animals.

\section{Virus and virus vaccine}

\section{MATERIALS AND METHODS}

A single pool of influenza virus A2/Hong Kong/3/68 (H3N2) was used for all ferret challenge experiments; the preparation and properties of this virus have been described previously (Potter et al. 1972a). Killed, monotypic influenza virus A2/Aichi/2/68 (H3N2) in saline (400 CCA units in 0.5 ml.) and the same virus concentration in adjuvant 65 were kindly supplied by Dr M. R. Hilleman (Merck Institute of Therapeutic Research, West Point, Pa.).

\section{Experimental design}

Groups of ferrets were inoculated intramuscularly with $400 \mathrm{CCA}$ units of killed influenza virus A2/Aichi/2/68 in saline or in adjuvant A65. The temperatures of the animals were taken twice daily for 4 days and subsequently daily for 3 days after immunization, as described previously (Potter et al. 1972a); the temperatures were also taken from a group of control ferrets which had not been immunized. Ferret nasal washings were collected on alternate days from day 5 to 15 after immunization for protein and antibody determination. Serum specimens were collected by cardiac puncture before immunization and 32-34 days after immunization.

Thirty-five days after immunization, the ferrets were inoculated intranasally under light ether anaesthesia with $10^{6.5}$ EID 50 of influenza virus A2/Hong Kong/ $3 / 68$; temperature readings and nasal washings were collected as described after immunization. Two temperature readings of $>40 \cdot 0^{\circ} \mathrm{C}$. occurring in the period 24-72 hr. after virus infection was taken as a significant temperature, and two temperature readings of $>1 \cdot 0^{\circ} \mathrm{C}$. rise above the mean pre-infection temperature was taken as a significant increase in temperature. In previous studies, nonimmunized ferrets consistently showed both a significant temperature and a significant increase in temperature following intra-nasal infection with influenza virus A2/Hong Kong/3/68 (Potter et al. 1972a). Nasal washings were collected three days after infection for virus isolation and 5-15 days after infection for protein and antibody determinations. A third serum specimen was obtained 28 days after virus infection. 


\section{Virus isolation}

Nasal washings taken 3 days after virus infection were stored at $-80^{\circ} \mathrm{C}$. in PBS containing $1 \%$ bovine serum albumin and antibiotics. The specimens were thawed, serial logarithmic dilutions were made in mixture ' $199^{\prime}$ ' and $0.1 \mathrm{ml}$. volumes inoculated into eggs by the allantoic route. After incubation at $36^{\circ} \mathrm{C}$. for $72 \mathrm{hr}$., the allantoic fluids were harvested and tested for virus haemagglutinin using $0.5 \%$ fowl cells. The titre of virus was estimated by the method of Reed and Muench (1938). The identity of each virus isolated from ferret nasal washings was established by haemagglutination-inhibition tests using specific ferret antisera.

\section{Nasal washings}

Ferret nasal washings were collected by washing the nose with PBS, as described previously (Potter et al. 1972a). Nasal washings, taken 5-15 days after immunization and after virus infection for protein and antibody studies, were shaken with glass beads and then centrifuged at 3000 r.p.m. for $10 \mathrm{~min}$. The supernatant fluids were concentrated 10-fold by dialysis against 30\% Carbowax, and stored at $-20^{\circ} \mathrm{C}$.

\section{Protein estimation}

The protein concentration of 10 -fold concentrated nasal washings was estimated by the method of Lowry, Rosebrough, Farr \& Randall (1951).

\section{Haemagglutination inhibition (HI) tests}

Haemagglutination-inhibition (HI) tests and neutralization tests were carried out by the methods described previously (Potter et al. 1972a).

\section{RESULTS}

The response to infection with virulent influenza virus $A 2 / H o n g ~ K o n g / 3 / 68$

Four ferrets, which had not been previously immunized, were infected with $10^{6.5}$ EID 50 of influenza virus A2/Hong Kong /3/68 by the intranasal route, under ether anaesthesia; this was carried out at the same time and using the same virus preparation that was used to challenge ferrets previously immunized with influenza A2/Aichi/2/68 vaccines. This virus inoculum produced a sharp increase in temperature for all four ferrets; for all four animals both a significant temperature and a significantly increased temperature were recorded (Fig. 1A, and Table 1). Nasal washings taken 3 days after virus infection all yielded virus; the titre of virus recovered in these specimens was $10^{5 \cdot 25}-10^{6 \cdot 25} \mathrm{EID} 50 / \mathrm{ml}$. After infection, all the animals were found to have high titres of serum HI antibody (Table 1).

Tests on ten-fold concentrated nasal washings taken 5-15 days after virus infection showed the presence of $\mathrm{HI}$ and neutralizing antibody in all the specimens taken 7 and 9 days after virus infection, and in three of the four specimens taken 11 days after infection. Antibody was not detected in nasal wash specimens taken five days after infection, or in specimens collected 13 and 15 days after virus infection (Fig. 2A). The concentration of protein in nasal washings increased to a 
Table 1. Response of ferrets to infection with influenza virus A2/Hong Kong/3/68

\begin{tabular}{|c|c|c|c|c|c|c|}
\hline \multirow{2}{*}{$\begin{array}{c}\text { Ferret } \\
\text { no. }\end{array}$} & \multicolumn{2}{|c|}{ Temperature } & \multirow{2}{*}{$\begin{array}{c}\text { Virus } \\
\text { isolation } \\
\text { (titre) } \dagger\end{array}$} & \multirow{2}{*}{$\begin{array}{l}\text { Change in } \\
\text { serum HI } \\
\text { titre }\end{array}$} & \multicolumn{2}{|c|}{ Change in nasal antibody* } \\
\hline & $>40 \cdot 0$ & $>1 \cdot 0$ rise & & & HI & Neut $\ddagger$ \\
\hline 174 & + & + & $+(5 \cdot 25)$ & $<5-800$ & $<5-20$ & $<2-40$ \\
\hline 175 & + & + & $+(5 \cdot 5)$ & $<5-1600$ & $<5-30$ & $<2-20$ \\
\hline 176 & + & + & $+(6 \cdot 25)$ & $<5-2400$ & $<5-40$ & $<2-60$ \\
\hline 177 & + & + & $+(5 \cdot 75)$ & $<5-800$ & $<5-40$ & $<2-40$ \\
\hline
\end{tabular}

* Change from pre-infection titre to peak, post-infection titre.

$\dagger \log _{10} \mathrm{EID}_{50} / \mathrm{ml}$.

$\ddagger$ Neutralization test.

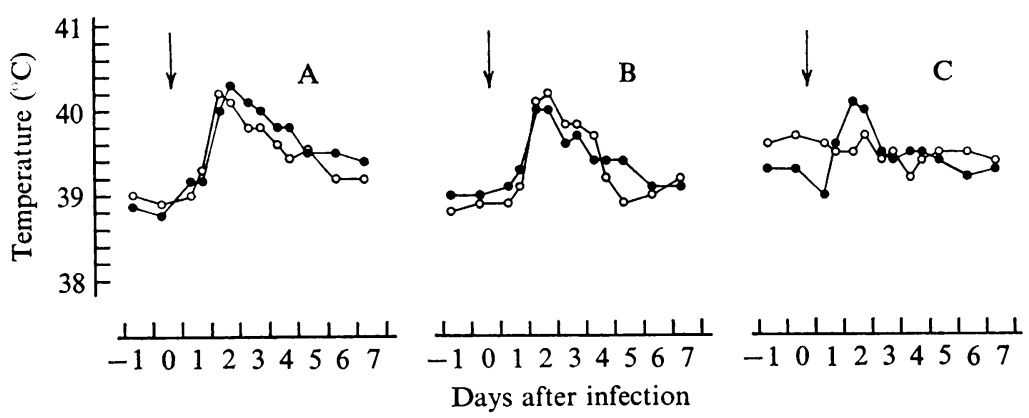

Fig. 1. Temperature response of ferrets to infection with influenza virus A2/Hong Kong/3/68. (A) Normal ferrets No. 174 and 177 (see Table 1). (B) Ferrets No. 162 and 171 (see Table 2) following immunization with $400 \mathrm{CCA}$ of inactivated A2/ Aichi/2/68 virus vaccine in saline. (C) Ferrets No. 164 and 166 (see Table 3) following immunization with $400 \mathrm{CCA}$ of inactivated A2/Aichi/2/68 virus vaccine in adjuvant 65. $\downarrow$ - Time of virus inoculation.

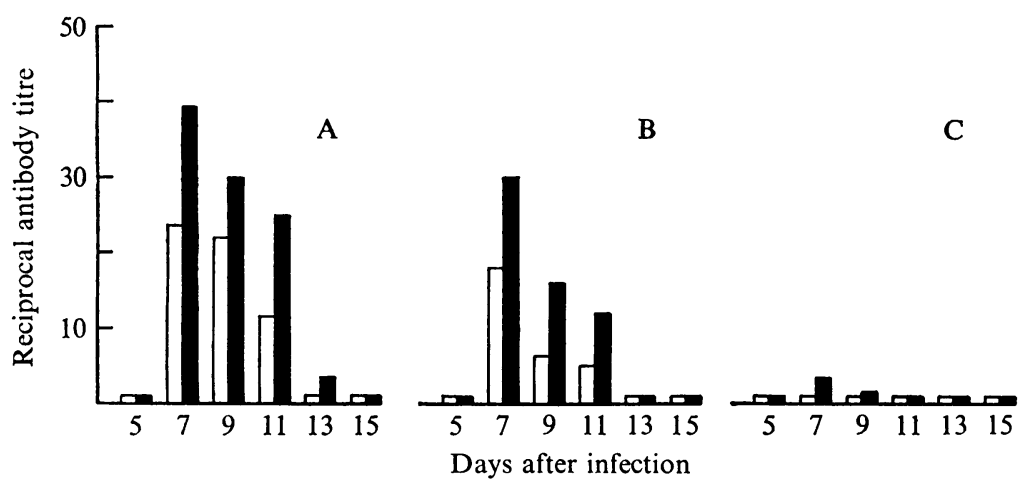

Fig. 2. Antibody titres in ferret nasal washings. Arithmetic mean titres of $\mathrm{HI}$ antibody $(\square)$ and neutralizing antibody $(\square)$ in $\times 10$ concentrated ferret nasal washings collected 5-15 days after intranasal infection with influenza virus A2/Hong Kong/ 3/68. (A) Normal ferrets. (B) Ferrets previously immunized with $400 \mathrm{CCA}$ of inactivated A2/Aichi/2/68 virus in saline. (C) Ferrets previously immunized with $400 \mathrm{CCA}$ of inactivated A2/Aichi/2/68 virus in adjuvant 65. 


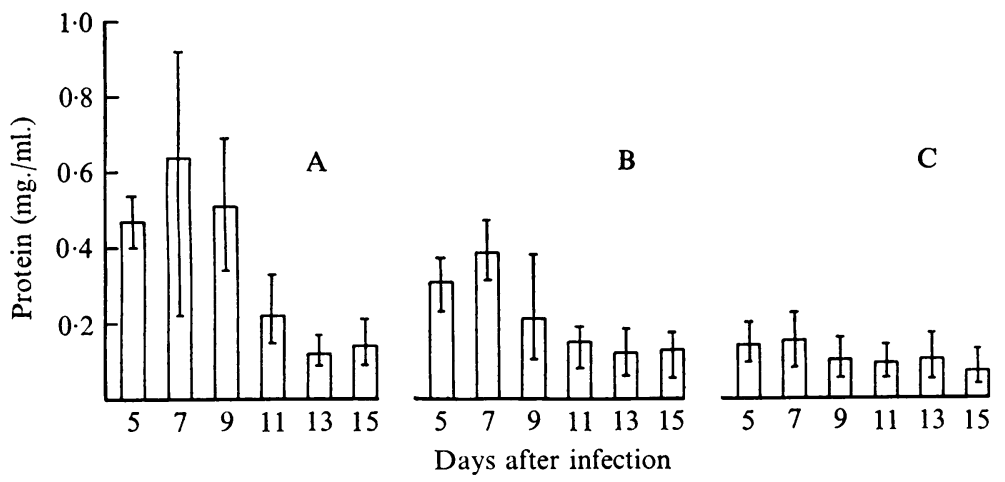

Fig. 3. Protein concentration in ferret nasal washings. Protein concentration of $\times 10$ concentrated ferret nasal washings collected 5-15 days after intranasal infection with influenza virus A2/Hong Kong/3/68. (A) Normal ferrets. (B) Ferrets previously immunized with $400 \mathrm{CCA}$ of inactivated A2/Aichi/2/68 virus vaccine in saline. (C) Ferrets previously immunized with $400 \mathrm{CCA}$ of inactivated A2/Aichi/2/68 virus vaccine in adjuvant 65. $\square$ mean protein concentration. I range of protein concentrations.

peak level at 7-9 days after virus infection; the level reached for individual animals was 3- to 5-fold greater than that found in pre-infection specimens (Fig. 3A). The protein concentration had fallen in specimens taken 9 days after infection, and the level for specimens collected 13-15 days post-infection was similar to that measured for uninfected ferrets.

\section{Response to immunization with killed A2/Aichi/2/68 vaccine}

\section{Response to immunization}

Four ferrets were each immunized with $400 \mathrm{CCA}$ units of killed influenza virus A2/Aichi/2/68 in an $0.5 \mathrm{ml}$. volume by the intramuscular route, and this inoculation caused a febrile reaction. Thus, in the period $24-72 \mathrm{hr}$. following immunization, all four ferrets had a measurable increase in temperature which subsequently fell to pre-inoculation levels; however, in only one case did the temperature exceed $40^{\circ} \mathrm{C}$. on two occasions, and in only one ferret did the temperature increase by $1 \cdot 0^{\circ} \mathrm{C}$. above the pre-inoculation level (Table 2). Immunization with the A2/Aichi/ $2 / 68$ in saline did not result in the production of detectable levels of $\mathrm{HI}$ or neutralizing antibody in the ferret nasal washings (Table 2), and the protein concentration of these specimens remained unchanged. The vaccine did not induce detectable levels of serum HI antibody to A2/Hong Kong virus in three of the four ferrets; serum HI antibody was detected at a relatively low titre in the remaining ferret (Table 2).

\section{Response to infection}

Thirty-five days after immunization with killed saline A2/Aichi/2/68 vaccine, the four ferrets were inoculated with influenza virus A2/Hong Kong/3/68. For all four animals, this infection was followed by a sharp temperature response (Fig. 1B and Table 2). Thus, all the animals showed both a significant temperature and a significant increased temperature in the period $24-72 \mathrm{hr}$. after virus infection. 


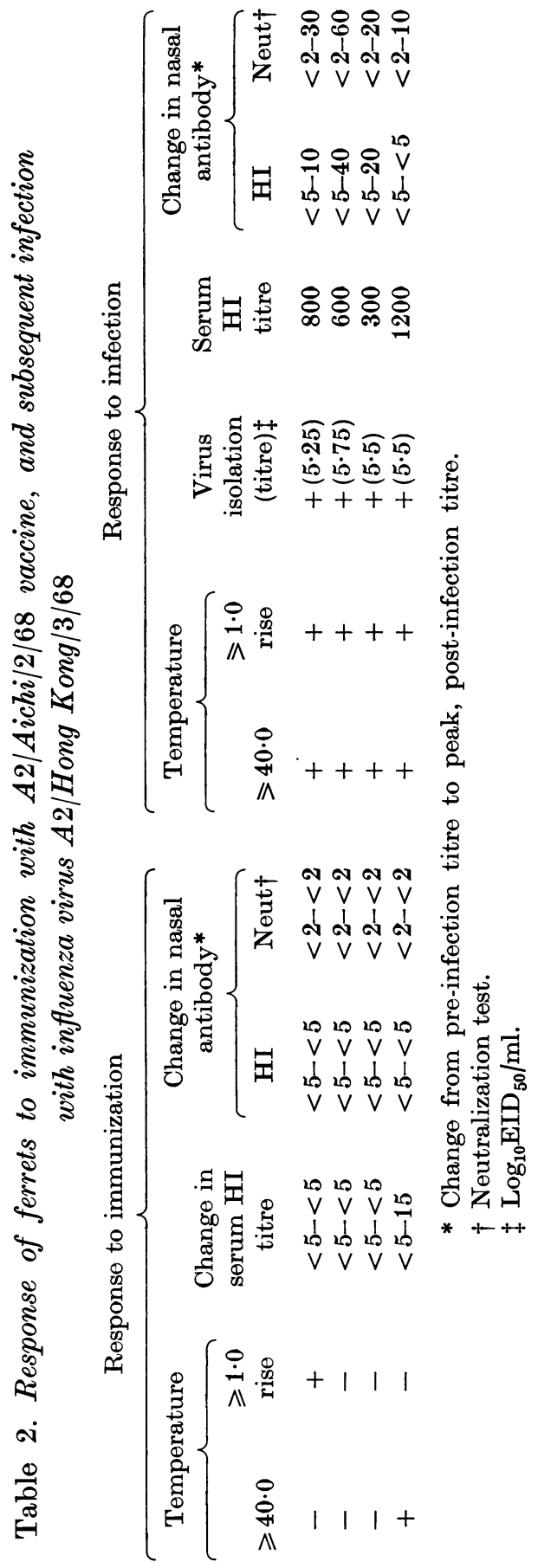

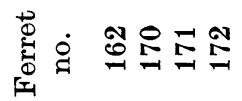

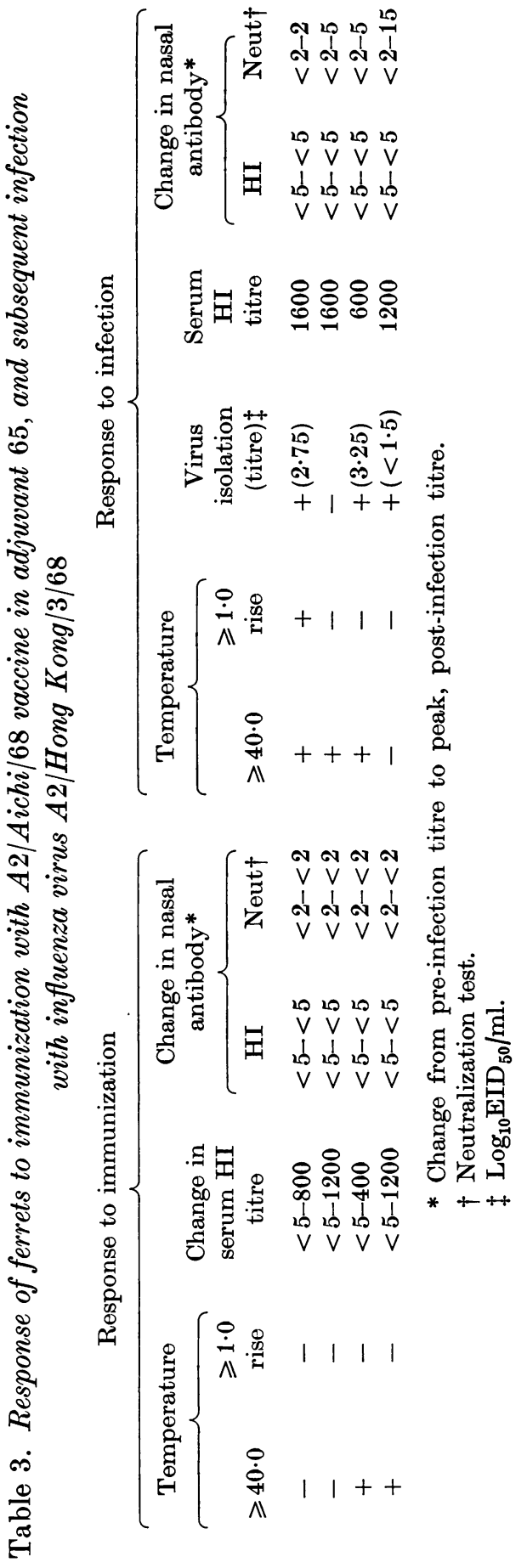

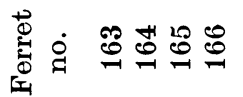


Virus was recovered from all four ferrets from nasal washings collected 3 days after virus infection; the titres of virus in these specimens were $10^{5 \cdot 25}-10^{5 \cdot 75} \mathrm{EID} 50 / \mathrm{ml}$. (Table 2). Serum specimens taken 21 days after virus infection from all four ferrets showed relatively high titres of $\mathrm{HI}$ antibody to A2/Hong Kong virus (Table 2).

The concentration of protein in nasal washings taken 5-15 days after virus infection showed that the levels had increased to a maximum at 7 days after infection; the maximum concentration of protein for individual ferrets at this time was 2- to 3-fold greater than that found in non-immunized ferrets (Fig. 3B). The protein levels in specimens taken 11-15 days after infection were similar to preinfection concentrations (Fig. 3B). Nasal washings taken 7 days after infection from three of the ferrets contained HI antibody, and in two of these ferrets HI antibody was also present in nasal washings taken on days 9 and 11 after infection (Fig. 2B). The remaining ferret was the animal which produced a low titre of serum HI antibody after immunization (Table 2), and nasal washings taken after challenge from this animal did not contain detectable $\mathrm{HI}$ antibody; however, nasal washings collected on day 7 and 9 after infection both contained low titres of neutralizing antibody.

\section{The response to immunization with killed $A 2 / A i c h i / 2 / 68$ in adjuvant $A 65$}

\section{Response to immunization}

Four ferrets were each immunized intramuscularly with $0.5 \mathrm{ml}$. of A2/Aichi/2/68 virus vaccine ( $400 \mathrm{CCA}$ units in adjuvant 65 ); this procedure resulted in a measurable febrile response in three of the animals. Thus, a significant temperature was recorded in two of the ferrets in the period $24-72 \mathrm{hr}$. after immunization, but none of the animals showed a significant increased temperature (Table 3). In contrast to the result with saline vaccine, immunization with killed A2/Aichi/2/68 virus in adjuvant 65 induced serum HI antibody, and serum specimens taken 32-34 days after immunization contained HI antibody titres of 1/400-1/1200 (Table 3). However, immunization did not result in the production of detectable HI or neutralizing antibody in nasal washings (Table 3). The protein concentration of nasal washings taken 5-15 days after immunization did not change significantly from pre-immunization values.

\section{Response to infection}

Thirty-five days after immunization with $\mathrm{A} 2 / \mathrm{Aichi} / 2 / 68$ vaccine in adjuvant 65 , the four ferrets were infected intranasally with $10^{6 \cdot 5}$ EID50 of influenza virus A2/Hong Kong/3/68. One ferret responded with both a significant temperature and a significant rise in temperature in the period 24-72 hr. after infection; however, the temperature response of the other three animals was modified (Fig. 1C, Table 3). Thus, for two ferrets a significant temperature was recorded but not a significant rise in temperature, and for the remaining animal the temperature remained normal (Table 3). Virus was recovered from nasal washings taken three days after infection from three of the four ferrets; the titres of virus recovered were $<10^{1 \cdot 5}-10^{3 \cdot 25} \mathrm{EID} 50 / \mathrm{ml}$, , and virus was not recovered from the remaining animal (Table 3). Thus, the titre of virus present in the nasal washings was 
significantly lower than that found in unimmunized ferrets or in ferrets previously immunized with saline vaccine (Tables 1 and 2).

Infection with virulent influenza virus A2/Hong Kong/3/68 did not result in a significant increase in serum HI antibody for ferrets previously immunized with the vaccine in adjuvant 65; for one ferret the titre increased two-fold, and for the other animals the titres were similar to those before infection. Tests on nasal washings taken 5-15 days after virus infection showed no significant increase in protein above the pre-infection values (Fig. 3C) and no detectable HI antibody (Fig. 2C). However, relatively low titres of neutralizing antibody were found in nasal washings taken 7 days after virus infection from all four ferrets and, for one ferret, in the nasal wash taken nine days after virus infection (Table 3 and Fig. $2 \mathrm{C}$ ). None of the specimens taken 5 days, or 11 or more days after virus infection contained detectable neutralizing antibody (Fig. 2C).

\section{DISCUSSION}

Previous studies have described the reaction of ferrets to infection with virulent influenza virus. The animals respond with both a significant temperature and a significant rise in temperature in the period 24-72 hr. after virus infection (Haff et al. 1966; Potter et al. 1972a). In addition, relatively high titres of virus were recovered in nasal washings of infected ferrets; there was a 3- to 5-fold increase in the concentration of protein in nasal washings; both neutralizing and $\mathrm{HI}$ antibody were detected in the ferret nasal washings; and the animals showed a significant rise in serum antibody (Potter et al. $1972 a, b$ ). Since immune ferrets do not exhibit these changes after infection (Potter et al. 1972a, b), the measurement of these changes can be used as a model system to assess immunity to, and immunizing methods against, influenza virus infection.

The influenza vaccine used in the present study produced a measurable febrile response in ferrets; since this was observed after immunization with both saline vaccine and vaccine in adjuvant 65 , this was attributable to the virus preparation, and not to adjuvant 65 .

The temperature response to infection with virulent influenza virus A2/Hong Kong/3/68 in ferrets which had been previously inoculated with $400 \mathrm{CCA}$ units of killed A2/Aichi/2/68 virus in saline was similar to that observed in non-immunized animals. Thus, immunization did not reduce the temperature response, and by this criterion immunization with this vaccine conferred no immunity to the challenge virus. In addition, the titre present in nasal washings taken 3 days after challenge was similar in both control and immunized ferrets. Three of the ferrets previously immunized with saline vaccine produced HI antibody in nasal washings after virus infection; the ferret which failed to produce nasal HI antibody was the animal which possessed a low titre of serum antibody before challenge. The concentration of protein and the titre of antibody present in the nasal washings after virus infection were measurably lower in ferrets immunized with saline vaccine than in control animals. Thus, although by two of five criteria the response of immunized ferrets to challenge was measurably less than that of control ferrets, the killed 
saline vaccine did not induce significant immunity to virus challenge. These findings were similar to the results obtained with a previous saline inactivated influenza virus vaccine (Potter et al. 1972a,b).

Immunization of ferrets with $400 \mathrm{CCA}$ units of influenza virus A2/Aichi/2/68 in adjuvant 65 resulted in relatively high titres of serum antibody, but no detectable nasal wash antibody. In this respect, the ferret findings were distinct from those obtained in man where immunization with inactivated influenza virus in adjuvant 65 has been reported to induce high titres of both serum and nasal antibody (Hilleman et al. 1972). After immunization, the ferrets gave a modified response to challenge with influenza virus A2/Hong Kong/3/68. The animals showed a measurably modified temperature response to virus infection and nasal washings contained reduced titres of virus. In addition, the titre of serum HI antibody did not significantly increase after infection with the challenge virus. Nasal washings taken 5-15 days after virus infection from all four ferrets showed relatively low titres of neutralizing antibody, but did not contain detectable HI antibody or increased protein concentration. Thus the ferrets, though not completely resistant to the challenge virus, showed a significantly modified response to influenza virus infection. The degree of immunity to challenge with influenza virus which was conferred by prior immunization with killed A2/Aichi/2/68 vaccine in adjuvant 65 was equivalent to that observed after immunization with killed A2/Hong Kong/3/ 68 vaccine in Freund's complete adjuvant (Potter et al. 1972b). Immunization with killed virus in either adjuvant A65 or in Freund's complete adjuvant induced titres of serum antibody similar to that observed after infection with live virus; however, the immunity which followed natural infection was complete, whilst that which followed immunization with killed virus in either adjuvant was not complete. This failure of killed virus vaccines to induce a solid immunity comparable to that found after infection with live virus may be due to the failure of the vaccines to elicit a local antibody response.

We wish to thank Professor Sir Charles Stuart-Harris for his advice and criticism, Dr M. R. Hilleman for the vaccines used in this study and Mrs D. Edey and Mrs L. Shepherd for their excellent technical assistance. The studies were supported by a grant from the Medical Research Council.

\section{REFERENCES}

Francis, T. \& Stuart-Harris, C. H. (1938). Studies on the nasal histology of epidemic influenza virus infection in the ferret. Journal of Experimental Medicine 68, 813.

Haff, R. F., Schriver, P. W. \& Stewart, R. C. (1966). Pathogenesis of influenza in ferrets. Nasal manifestation of disease. British Journal of Experimental Pathology 48, 435.

Hilleman, M. R., Woodhour, A. F., Friedman, A., Weibel, R. E. \& Stokes, J. JR. (1972). The clinical application of adjuvant 65. Annals of Allergy 30, 152.

Lowry, O. H., Rosebrough, N. J., Farr, A. L. \& Randall, R. J. (1951). Protein measurement with Folin phenol reagent. Journal of Biological Chemistry 193, 265.

Marois, P., Boudreault, A., Difranco, E. \& Pavizanis, V. (1971). Response of ferrets and monkeys to intranasal infection with human, equine and avian influenza viruses. Canadian Journal of Comparative Medicine 35, 71. 
Potter, C. W., Oxford, J. S., Shore, S. L., McLaren, C. \& Stuart-Harris, C. H. (1972a). Immunity to influenza in ferrets. I. Response to live and killed virus. British Journal of Experimental Pathology 53, 153.

Potter, C. W., Shore, S. L., McLaren, C. \& Stuart-Harris, C. H. (1972b). Immunity to influenza in ferrets. II. Influence of adjuvants on immunization. British Journal of Experimental Pathology 53, 168.

Reed, L. J. \& Muench, H. (1938). A simple method of estimating fifty per cent endpoints. American Journal of Hygiene 27, 493.

Smith, W., Andrewes, C. H. \& Laidlaw, P. P. (1933). A virus obtained from influenza patients. Lancet ii, 66.

Stokes, J. Jr., Werbel, R. E., Woodhour, A. F., McAleer, W. J., Potkonski, L. A. \& Hilleman, M. R. (1969). Metabolizable immunologic adjuvant for human use. Journal of the American Medical Association 207, 2067.

Weibel, R. E., Woodhour, A. F., Stokes, J. Jr., Metzgar, D. P. \& Hilleman, M. R. (1967). New metabolizable immunologic adjuvant for human use. New England Journal of Medicine 276, 78.

Woodhour, A. F., McAleer, W. J., Friedman, A., Weibel, R. E., Stokes, J. Jr. \& Hilleman, M. R. (1969). Antibody responses in man to Hong Kong influenza following 1967 formula influenza vaccine in adjuvant A65. Proceedings of the Society for Experimental Biology and Medicine 131, 501. 